\title{
Thermal Stability of $\mathrm{CsPbBr}_{3}$ Perovskite Quantum Dots Assembled with SBA-15
}

\author{
Hongyu Chen ${ }^{1}$, Yunfei Wang ${ }^{1}$, Jianing Wang ${ }^{2}$ and Wenyan Liu ${ }^{1,3, *}$ \\ 1 Department of Physics, School of Sciences, Beihua University, Jilin 132013, China; \\ hyuchen0309@163.com (H.C.); w211616@126.com (Y.W.) \\ 2 Changchun Institute of Optics, Fine Mechanics and Physics, Chinese Academy of Sciences, \\ Changchun 130033, China; qazedcfv@sina.com \\ 3 Department of Materials Science and Engineering, Beihua University, Jilin 132013, China \\ * Correspondence: wyliu1234@163.com; Tel.: +86-186-0449-5978
}

Citation: Chen, H.; Wang, Y.; Wang,

J.; Liu, W. Thermal Stability of $\mathrm{CsPbr}_{3}$ Perovskite Quantum Dots Assembled with SBA-15. Coatings 2021, 11, 953. https://doi.org/ 10.3390/coatings11080953

Academic Editor: Xiaoyu Zhang

Received: 17 July 2021

Accepted: 6 August 2021

Published: 9 August 2021

Publisher's Note: MDPI stays neutral with regard to jurisdictional claims in published maps and institutional affiliations.

Copyright: (C) 2021 by the authors. Licensee MDPI, Basel, Switzerland. This article is an open access article distributed under the terms and conditions of the Creative Commons Attribution (CC BY) license (https:// creativecommons.org/licenses/by/ $4.0 /)$.

\begin{abstract}
Nowadays, the excellent performance of metal halide perovskite quantum dots (PQDs) has been demonstrated, but the stability is still a perplexing issue. In this paper, the $\mathrm{CsPbBr}_{3} \mathrm{QDs}$ were assembled into SBA-15 for the first time. The thermal stability and photoluminescence (PL) intensity of SBA-15@CsPbBr 3 QDs were improved. The PL spectra of pure $\mathrm{CsPbBr}_{3}$ QDs have red-shift ( 6 nm) with the increasing temperature. However, that of SBA-15@CsPbBr 3 QDs have almost no red-shift. The PL intensity of SBA-15@CsPbBr 3 QDs decreased slightly after heating and cooling for several times. By comparison, the PL intensity of pure $\mathrm{CsPbBr}_{3}$ QDs decreased more significantly. The experimental results showed that SBA-15 played a significant role in improving the thermal stability of PQDs, which will have an excellent potential for the application of PQDs in the future.
\end{abstract}

Keywords: $\mathrm{CsPbrr}_{3}$ QDs; SBA-15; thermal stability

\section{Introduction}

Recently, the global demand for lighting, display and other fields has increased sharply [1]. It has been found that semiconductor light-emitting diodes (LED) are more energy efficient than traditional lighting display devices [2-4]. However, LED devices made from conventional inorganic semiconductor materials need to strictly control the preparation conditions, and their production and efficiency are limited by high production costs and high ohmic contact resistance [5-7]. Organic light-emitting diodes (OLED), by contrast, greatly improve the relevant performance, but their efficiency will be reduced at high current densities [8]. Therefore, perovskite has been widely concerned in the field of optoelectronics due to its advantages of tunable band gap, high light absorption coefficient, small exciton binding energy and high charge mobility. It is generally believed that perovskite materials an ideal direct band gap semiconductor as raw material for lightemitting devices [9]. Metal halide perovskites (MHPs) have become a new generation of light-emitting materials due to their fantastic optoelectronic properties, such as high color purity, tunable band gaps, bipolar conduction, etc. [10].

Semiconductor quantum dots (QDs) are becoming the focus of research due to their unique properties [8,11-13]. Quantum limiting effect is the most significant characteristic of QDs [14,15]. The three-dimensional (3D) quantum limiting effect of carriers in quantum dots is caused by low density of state and high energy level sharpness, which also changes the electrical and optical properties of quantum dots [16]. Semiconductor QDs have an excellent promise for wide application such as in single electronic devices, memory devices and various optoelectronic devices due to the properties above [17].

Metal halide perovskite quantum dots are zero-dimensional nano materials, which have tunable emission spectrum, high light stability and long fluorescence lifetime due to quantum limiting effect [18]. Especially, lead halide perovskite nanocrystals are suitable for 
solid-state lighting and high-definition display applications due to their wide color gamut (NTSC $\approx 140 \%$ ) [19,20], high color purity [21], as well as facile synthesis methods [22-25]. The external quantum efficiency (EQE) of LEDs based on perovskite quantum dots mainly depends on the quality of the luminescent layer, and the quality can be improved by optimizing the preparation method and adjusting the composition [26-30]. Compared with 2D and 3D perovskite, the perovskite quantum dot films have many advantages, such as high color gamut, pure color, stable performance and so on. Therefore, the photovoltaic devices based on the perovskite quantum dot films will have better performance [31]. However, the thermal stability of PQDs has been restricting their development [32].

There are many factors which are affecting the thermal stability of PQDs, the most important is the uneven grain size distribution [33], which leads to the increase of defects in the crystal. During the continuous heating process, the internal stress inhomogeneity of PQD lattice begins to produce, which makes the lattice distorted until the perovskite structure begins to collapse [34]. Therefore, we believe that the fundamental way to solve this problem is to adopt a new method to synthesize quantum dots [35-37], so that their grain distribution is more uniform with good dispersion. Template synthesis is one of the feasible methods at present, which is using mesoporous materials as template to make the synthesized PQDs' grains have better dispersion, thus reducing the internal defects of the crystal lattice, greatly reducing the internal stress of the crystal lattice and improving the thermal stability [38,39].

SBA series mesoporous silicon materials are named from the University of California, Santa Barbara, which is the abbreviation of Santa Barbara amorphous [40]. Among them, SBA-15 is more famous. SBA-15 is a mesoporous silica with a fine pore diameter arrangement and controllable pore diameter between 5 to $15 \mathrm{~nm}$ [41]. SBA- 15 compared with older mesoporous silica has larger pores and thicker walls (3.1-6.4 nm), these make SBA-15 yields with good thermal, mechanical stability and chemical resistance properties [42]. The structure of SBA-15 is an ordered hexagonal and it was also synthesized using triblock copolymer. The surface area of neat SBA-15 could be up to $650 \mathrm{~m}^{2} / \mathrm{gr}[43,44]$.

In this paper, we synthesized the PQDs by ligand assisted precipitation (LAPR) method at room temperature and using SBA-15 as a template. By using SBA-15 as a template, the growth of PQDs during the preparation process was strictly controlled to make its crystallization more uniform, thus improving the thermal stability and the intensity of PL spectra of PQDs.

\section{Materials and Methods}

\subsection{Experimental Materials}

Cesium bromide (CsBr, 99.9\%, Aladdin Industrial Corporation, Shanghai, China), lead (II) bromide $\left(\mathrm{PbBr}_{2}, 99.0 \%\right.$, Aladdin Industrial Corporation, Shanghai, China), oleic acid (OA, 90\%, Aladdin Industrial Corporation, Shanghai, China), oleylamine (OLA, 90\%, from Aladdin Industrial Corporation, Shanghai, China), N,N-dimethylformamide (DMF, 99.9\%, Sigma-Aldrich, Shanghai, China), hexane (99\%, Aladdin Industrial Corporation, Shanghai, China), ethyl alcohol (99.7\%, Aladdin Industrial Corporation, Shanghai, China), 1-octadecene (ODE, 99.5\%, Aladdin Industrial Corporation, Shanghai, China) SBA-15 (6$11 \mathrm{~nm}$, Jiangsu XFNANO Materials Tech, Nanjing, China), $\mathrm{KnNa}_{12-\mathrm{n}}\left(\left(\mathrm{AlO}_{2}\right)_{12}\left(\mathrm{SiO}_{2}\right)_{12}\right) \cdot \times \mathrm{xH}_{2} \mathrm{O}$ (molecular sieves, $3 \AA$, Aladdin Industrial Corporation, Shanghai, China). DMF (SigmaAldrich, Shanghai, China), hexane (Aladdin Industrial Corporation, Shanghai, China), ODE (Aladdin Industrial Corporation, Shanghai, China) and ethyl alcohol (Sigma-Aldrich, Shanghai, China) are added to $\mathrm{K}_{\mathrm{n}} \mathrm{Na}_{12-\mathrm{n}}\left(\left(\mathrm{AlO}_{2}\right)_{12}\left(\mathrm{SiO}_{2}\right)_{12}\right) \cdot \mathrm{xH}_{2} \mathrm{O}$.

\subsection{Synthesis of $\mathrm{CsPbBr}_{3} \mathrm{QDs}$}

As shown in Scheme 1, perovskite nanocrystals were synthesized by LAPR method at room temperature; $0.043 \mathrm{~g}(0.2 \mathrm{mmol}) \mathrm{CsBr}$ and $0.073 \mathrm{~g}(0.2 \mathrm{mmol}) \mathrm{PbBr}_{2}$ were dissolved in DMF $(5 \mathrm{~mL}), \mathrm{OA}(0.5 \mathrm{~mL})$ and OLA $(0.25 \mathrm{~mL})$, and the precursor solution was obtained. The precursor solution was stirred until all the solids were dissolved and a clear solution was 
obtained; $1 \mathrm{~mL}$ of the precursor mixture was injected into $10 \mathrm{~mL}$ of hexane in a centrifuge tube, adding $10 \mathrm{~mL}$ of anhydrous ethanol and centrifuged at $6000 \mathrm{rpm}$ for $6 \mathrm{~min}$. Finally, the supernatant was dumped and the $\mathrm{CsPbBr}_{3}$ QDs was collected for further characterization.

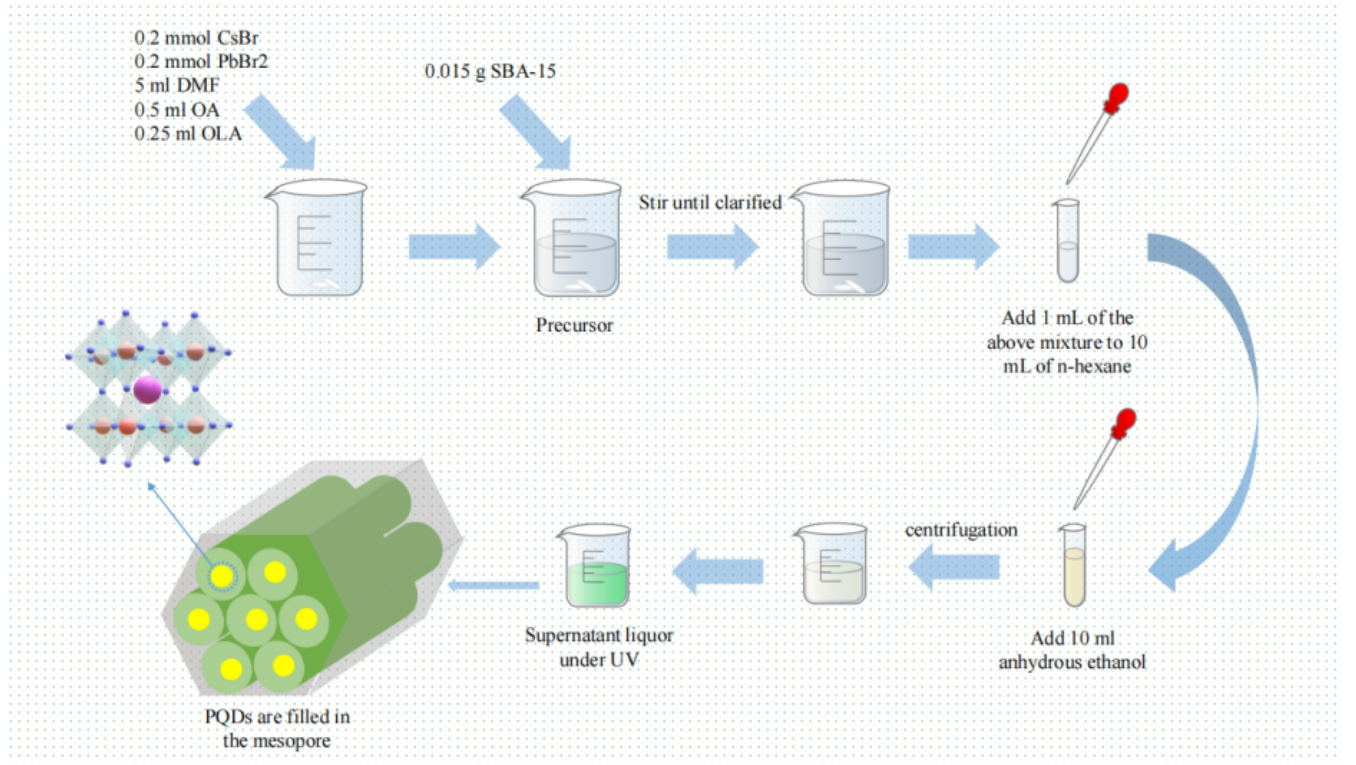

Scheme 1. Schematic illustration of formation of SBA-15@CsPbBr 3 QDs.

\subsection{Synthesis of SBA-15@CsPbBr 3 QDs}

Solutions containing SBA-15@CsPbBr 3 QDs were prepared using the method described in Section 2.2. Then, $0.015 \mathrm{~g}$ of SBA-15 was added to the precursor and the mixture was stirred until all the solids were dissolved completely. Following, $1 \mathrm{~mL}$ of the mixture was injected into $10 \mathrm{~mL}$ of hexane. The products were centrifuged at $6000 \mathrm{rpm}$ for $12 \mathrm{~min}$. Finally, the supernatant was dumped and the SBA-15@CsPbBr 3 QDs was collected for further characterization.

\subsection{Characterizations}

The X-ray diffraction (XRD) patterns of the $\mathrm{CsPbBr}_{3}$ QDs and $\mathrm{SBA}-15 @ \mathrm{CsPbBr} 3$ QDs were measured by a $\mathrm{Cu} \mathrm{K} \alpha$ radiation using XRD-6100 (X'Pert PRO, PANalytical, Amsterdam, The Netherlands). Fourier Transform Infrared (FTIR) spectra were performed using KBr tablets and a Nicolet iS50 FT-IR Spectrometer (Thermo Fisher Scientific, Waltham, MA, USA). The transmission electron microscope (TEM) images were recorded by a transmission electron microscope (JEM 2100F, JEOL, Tokyo, Japan). For the characterization of TEM, the samples were formed film on the ultra-thin carbon film. The Energy Dispersive Spectrometer (EDS) spectra were measured by scanning electron microscope (SEM), (UHR FE-SEM SU8000, Hitachi High-Technologies, Tokyo, Japan). Absorption spectra were measured by a UV-Vis spectrophotometer (UV-2700, Bruker, Karlsruhe, Germany). The samples were dissolved in hexane. Photoluminescence (PL) spectra were measured by a fluorescence spectrophotometer (Omni PL-BH, Zolix, Beijing, China), a $405 \mathrm{~nm}$ laser was used as the excitation source. All tests above were done at room temperature. For temperature-dependent PL spectra, the samples were dissolved in 1-octadecene.

\section{Results and Discussion}

The absorption and PL spectra of $\mathrm{CsPbBr}_{3}$ QDs and SBA-15@CsPbBr 3 QDs were shown in Figure 1. As shown in Figure 1a, the absorption peaks of $\mathrm{CsPbBr}_{3}$ QDs and SBA$15 @ \mathrm{CsPbBr} 3$ QDs were $498 \mathrm{~nm}$ and $515 \mathrm{~nm}$, respectively. The red-shift of the absorption peaks was due to the adsorption of QDs on the surface of SBA-15 and the formation of slightly bigger particles. The PL spectra of $\mathrm{CsPbBr}_{3}$ QDs and SBA-15@CsPbBr 3 QDs at the same concentration was shown in Figure 1b. At the excitation wavelength of $405 \mathrm{~nm}$, 
the PL intensity of $\mathrm{CsPbBr}_{3}$ QDs was slightly lower than SBA-15@CsPbBr 3 QDs, and the latter produced a slight red-shift. The emission wavelength of pure $\mathrm{CsPbBr}_{3} \mathrm{QDs}_{\mathrm{S}}$ and SBA-15@CsPbBr 3 QDs were 515 nm and 519 nm, respectively. A red-shift of $4 \mathrm{~nm}$ occurred; this might be due to the increased size of SBA-15 when it was assembled with $\mathrm{CsPbBr}_{3}$ QDs. Additionally, their narrow full width at half maxima (FWHM) were around $22 \mathrm{~nm}$ and $23 \mathrm{~nm}$, respectively. There was no significant change in FWHM due to the introduction of SBA-15. The photoluminesence quantum yield (PLQY) of $\mathrm{CsPbBr}_{3}$ QDs was $50 \%$ and that of SBA-15@CsPbBr 3 QDs was 60\%. The PLQY and temperature dependence PLQY have been measured. The PLQY of the two samples at different temperatures was compared. The quantum efficiency with different temperatures have been measured. The PLQY of $\mathrm{CsPbBr}_{3}$ QDs remained $\sim 7 \%$ of initial PLQY at $70{ }^{\circ} \mathrm{C}$. In contrast, the PLQY of SBA-15@CsPbBr 3 remained $\sim 21 \%$ of initial PLQY at $70{ }^{\circ} \mathrm{C}$. The mesoporous of SBA-15 are open channel. Therefore, the air and water also can influence the PL intensity of SBA-15@CsPbBr $\mathrm{PD}_{3}$. However, as a template, SBA-15 can inhibit the agglomeration of quantum dots during heating, which can be proved from the fact that the position of PL peak hardly changes with the increasing temperature.
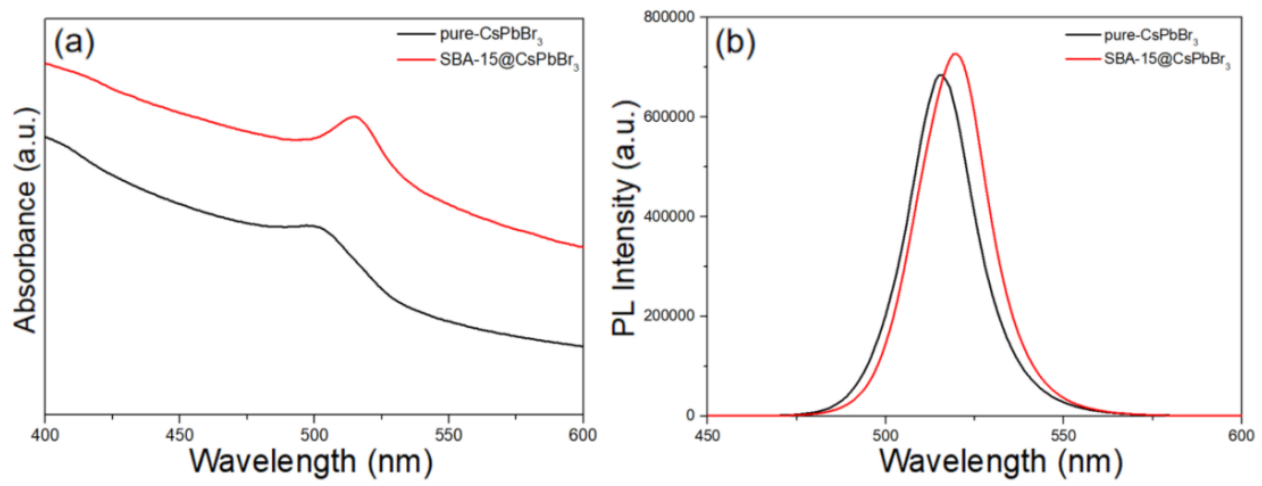

Figure 1. (a) UV-Vis absorption of pure $\mathrm{CsPbBr}_{3}$ QDs (black) and $\mathrm{SBA}-15 @ \mathrm{CsPbBr}_{3} \mathrm{QDs}$ (red); (b) PL spectra of pure $\mathrm{CsPbr}_{3}$ QDs (black) and SBA-15@CsPbBr 3 QDs (red).

The TEM photographs were shown in Figure 2a,b, which indicate the particle sizes of $\mathrm{CsPbBr}_{3}$ QDs and SBA-15@CsPbBr 3 QDs which were 3 and $6 \mathrm{~nm}$, respectively. The size and distribution of $\mathrm{CsPbBr}_{3}$ QDs and SBA-15@CsPbBr 3 QDs were shown in Figure 2c,d. In Figure 3, the energy-dispersive spectroscopy (EDS) elemental mapping of the $\mathrm{CsPBBr}_{3}$ QDs and SBA-15@CsPbBr 3 QDs films are shown. As shown in Figure 3i,j, from which a distribution of $\mathrm{Si}$ elements in the selected square area was clearly seen, the EDS peak of $\mathrm{Si}$ has been observed in SBA-15@CsPbBr 3 QDs. The mole fraction of each element in $\mathrm{CsPbBr}_{3}$ QDs and SBA-15@CsPbBr 3 QDs was shown in Table 1. The mole fraction of Si was 0 in $\mathrm{CsPbBr}_{3}$ QDs and 30.7 in SBA-15@CsPbBr 3 QDs.

For further research, FTIR spectra of pure $\mathrm{CsPbBr}_{3}$ QDs and SBA-15@CsPbBr $\mathrm{PbD}_{3}$ QD were measured, as shown in Figure 4. The peaks at around 3414 and $1626 \mathrm{~cm}^{-1}$ were found in the FTIR spectra of pure $\mathrm{CsPbBr}_{3}$ QDs and SBA-15@CsPbBr 3 QDs, and there were the symmetric stretching of $\mathrm{N}-\mathrm{H}$ bond and the asymmetric of $\mathrm{NH}^{+}$, respectively. The peaks at $2853 \mathrm{~cm}^{-1} / 2857 \mathrm{~cm}^{-1}$ and $2923 \mathrm{~cm}^{-1} / 2927 \mathrm{~cm}^{-1}$ were attributed to C-H tensile vibrations of the ligands of pure $\mathrm{CsPbBr}_{3}$ QDs and SBA-15@CsPbBr 3 QDs. For the red curve in Figure 4, there were two obvious peaks at 797 and $1095 \mathrm{~cm}^{-1}$, which correspond to the symmetric and anti-symmetric tensile vibration modes of the $\mathrm{Si}-\mathrm{O}-\mathrm{Si}$ group of SBA-15@CsPbBr 3 QDs. A peak of $1390 \mathrm{~cm}^{-1}$ was corresponded to $\mathrm{CH}_{3}$ vibration mode. The peaks of $968 \mathrm{~cm}^{-1}$ and $1651 \mathrm{~cm}^{-1}$ were related to vibration of $\mathrm{Si}-\mathrm{OH}$ and $\mathrm{H}-\mathrm{OH}$ group. The existence of $\mathrm{H}-\mathrm{OH}$ bond indicated that the $\mathrm{CsPBr}_{3}$ QDs were dispersed in the mesoporous channels of SBA- 15 . 
(a)

(c)
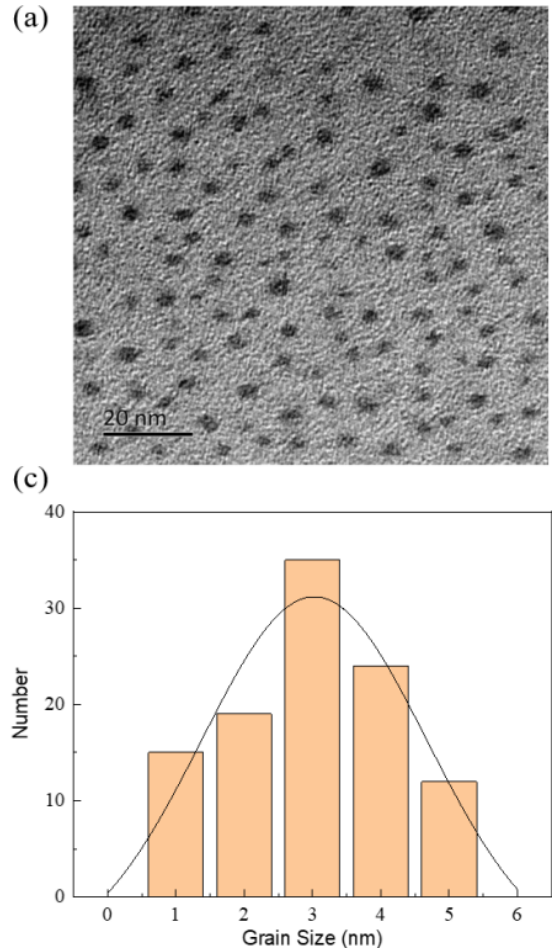

(b)

(d)
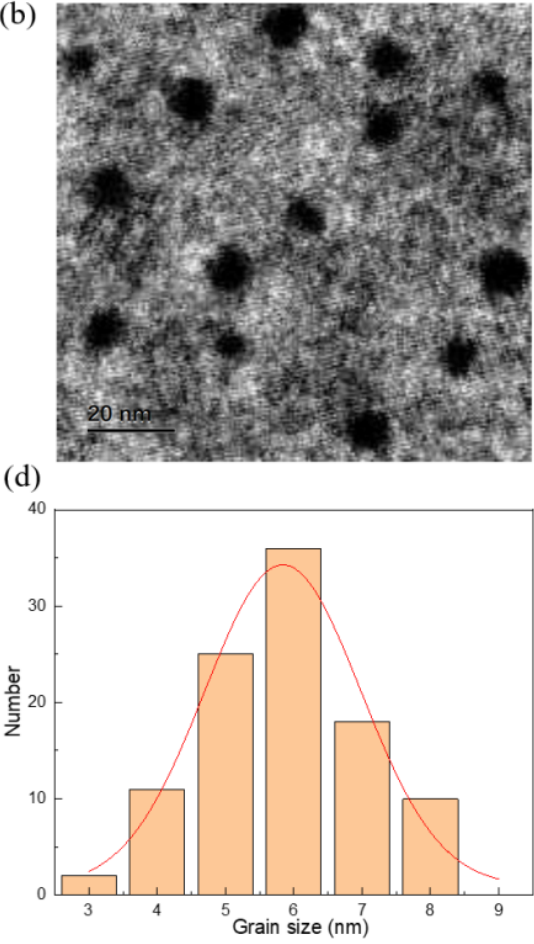

Figure 2. TEM images and distribution of grain size of pure $\mathrm{CsPbBr}_{3} \mathrm{QDs}(\mathbf{a}, \mathbf{c})$ and $\mathrm{SBA}-15 @ \mathrm{CsPbBr}$ QDs (b,d).

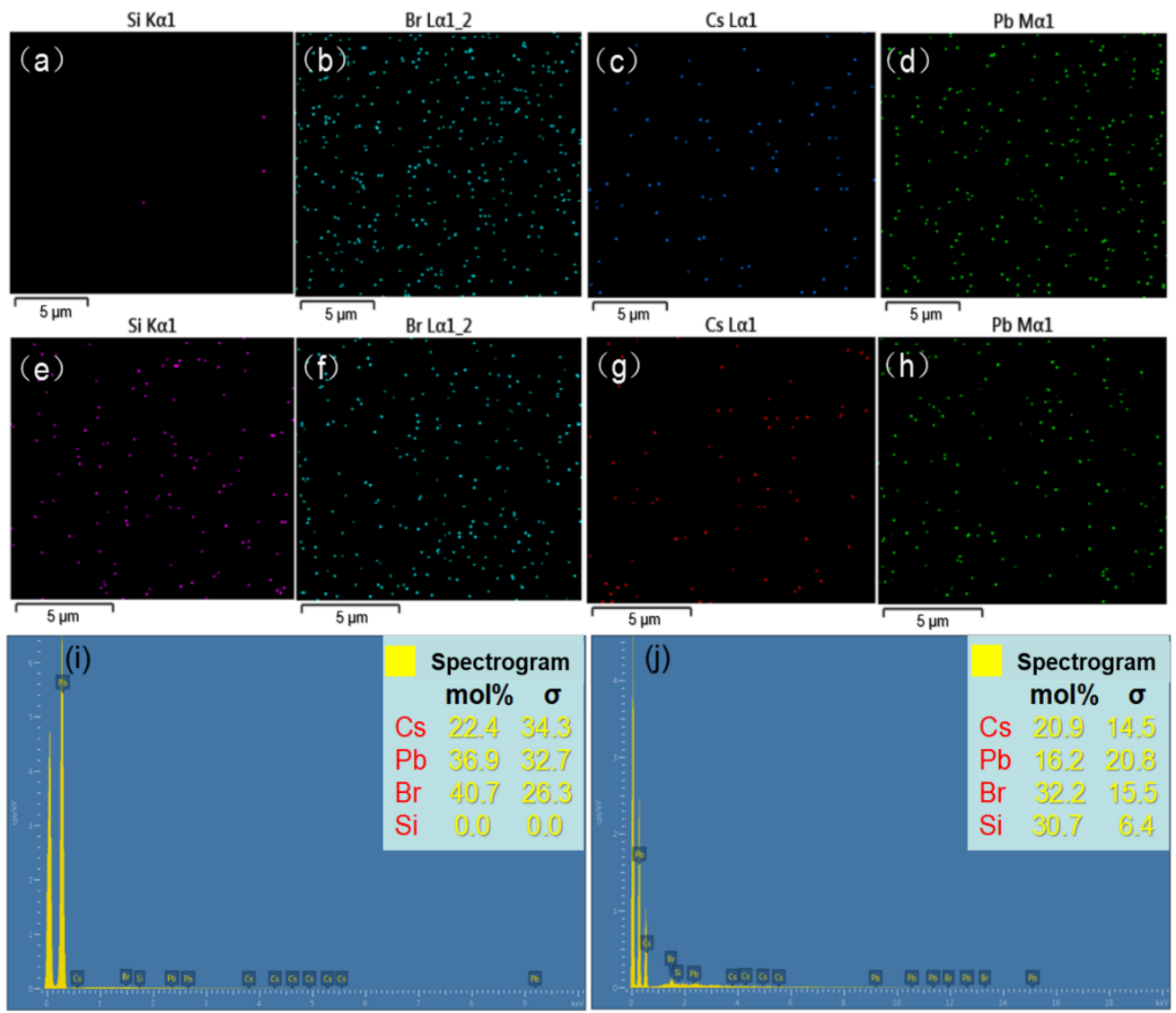

Figure 3. The EDS images of $\mathrm{CsPbBr}_{3}$ QDs (a-d) and SBA-15@CsPbBr 3 QDs (e-h). The elemental proportion of $\mathrm{CsPbBr}_{3}$ QDs (i) and SBA-15@CsPbBr 3 QDs (j). 
Table 1. The elemental mole fraction of $\mathrm{CsPbBr}_{3}$ QDs and SBA-15@CsPbBr 3 QDs.

\begin{tabular}{ccc}
\hline Atoms & $\mathrm{CsPbBr}_{\mathbf{3}}(\mathbf{m o l} \%)$ & SBA-15@CsPbBr $_{\mathbf{3}}(\mathbf{m o l} \%)$ \\
\hline $\mathrm{Cs}$ & 22.4 & 20.9 \\
$\mathrm{~Pb}$ & 36.9 & 16.2 \\
$\mathrm{Br}$ & 40.7 & 32.2 \\
$\mathrm{Si}$ & 0 & 30.7 \\
\hline
\end{tabular}

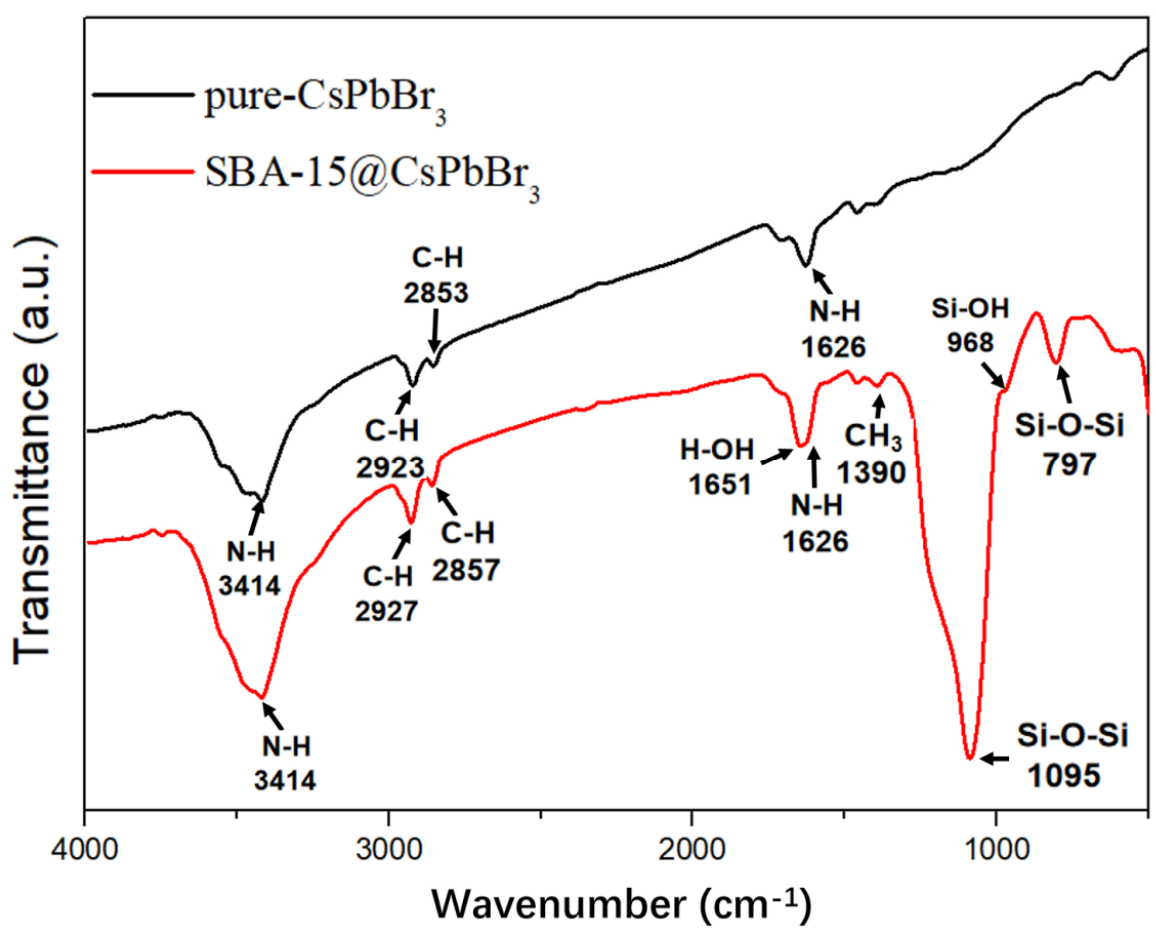

Figure 4. FTIR of (black) $\mathrm{CsPbBr}_{3}$ QDs and (red) SBA-15@CsPbBr 3 QDs.

The XRD images of pure $\mathrm{CsPbBr}_{3}$ QDs and SBA-15@CsPbBr 3 QDs were shown in Figure 5. The black curve of pure $\mathrm{CsPbBr}_{3}$ QDs showed strong diffraction peaks at $15.19^{\circ}$, $21.55^{\circ}, 30.65^{\circ}, 34.37^{\circ}, 37.77^{\circ}$ and $43.89^{\circ}$, corresponding to cubic $\mathrm{CsPbBr}_{3}$ (PDF\#00-054-0752) (100), (110), (200), (210), (211) and (220) planes, respectively. Comparing to the two XRD curves, it was found that all the characteristic peaks of pure $\mathrm{CsPBBr}_{3}$ QDs could be found in the curve of SBA-15@CsPbBr 3 QDs, which indicated that the structure of pure $\mathrm{CsPbBr}_{3}$ QDs was preserved without destruction after assembling into SBA-15.

Figure 6 showed the temperature-dependent $\mathrm{PL}$ spectra of pure $\mathrm{CsPbBr}_{3}$ QDs and SBA$15 @ \mathrm{CsPbBr}_{3} \mathrm{QDs}$ at room temperature-100 ${ }^{\circ} \mathrm{C}$ under the same environment conditions. The PL spectra of SBA-15@CsPbBr 3 QDs decreased less than that of $\mathrm{CsPbBr}_{3}$ QDs with increasing temperature, especially at lower temperature, although the PL intensity of both materials decreased significantly. The peak position of pure $\mathrm{CsPbBr}_{3}$ QDs moved from $515 \mathrm{~nm}$ (RT) to $521 \mathrm{~nm}$ with the increasing temperature. Nevertheless, the peak position of SBA-15@CsPbBr 3 QDs was 519 nm and there was almost no red-shift in the peak position. The data above proved that the thermal stability of $\mathrm{SBA}-15 @ \mathrm{CsPbBr} 3$ QDs was better than that of pure $\mathrm{CsPbBr}_{3}$ QDs. 


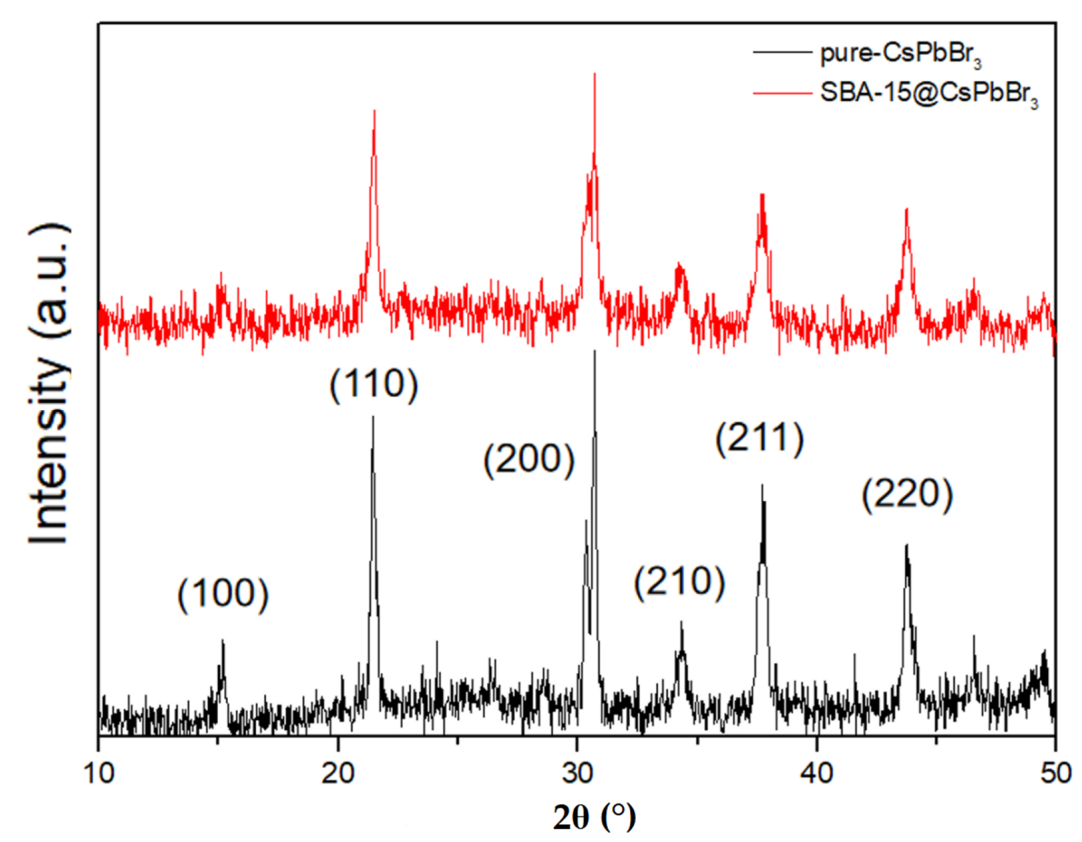

Figure 5. XRD pattern of pure $\mathrm{CsPbBr}_{3}$ QDs (black) and SBA-15@CsPbBr 3 QDs (red).
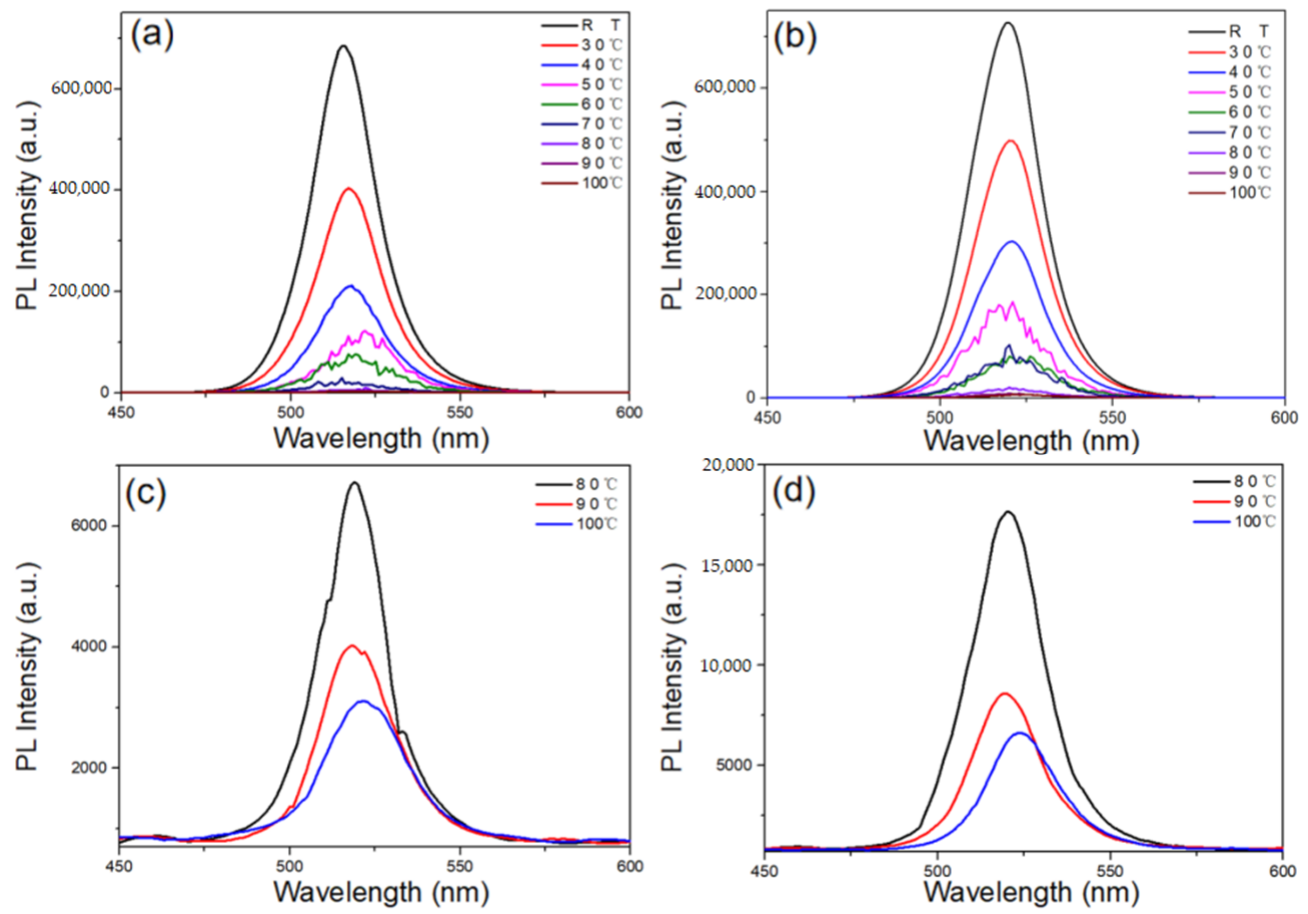

Figure 6. PL spectra of (a) pure $\mathrm{CsPbBr}_{3}$ QDs and (b) SBA-15@CsPbBr 3 QDs from room temperature to $100{ }^{\circ} \mathrm{C}$; PL spectra of (c) pure $\mathrm{CsPbBr}_{3}$ QDs and (d) SBA-15 CsPbBr 3 QDs at 80, 90, and $100{ }^{\circ} \mathrm{C}$.

The PL spectra of the pure $\mathrm{CsPbBr}_{3}$ QDs and SBA-15@CsPbBr 3 QDs with the number of cycles were shown in Figure 7. The PL spectrum was measured after PQDs was raised to $100{ }^{\circ} \mathrm{C}$ and cooled to room temperature. As shown in Figure $7 \mathrm{a}$, the PL intensity of pure $\mathrm{CsPbBr}_{3}$ QDs falling back to room temperature after the second rise to $100{ }^{\circ} \mathrm{C}$ was about a quarter of that of the first. In addition, the PL intensity decreased significantly after each heating and cooling cycle, and the luminescence was very weak which was shown in Figure 7c. By contrast, the PL intensity of SBA-15@CsPbBr 3 QDs was a third of the first after two times of heating to $100{ }^{\circ} \mathrm{C}$ and cooling to room temperature which was shown in Figure 7b. The PL intensity of $\mathrm{CsPbBr}_{3}$ QDs and SBA-15@CsPbBr 3 QDs 
decreased significantly mainly due to the falling of ligands (OA or OLA) from the surface of QDs and the additional structural defects caused by the first thermal cycle. Therefore, the PL intensity after first thermal cycle decreased more significantly than that of second, third and fourth time thermal cycle. Compared with $\mathrm{CsPbBr}_{3}$ QDs, the PL intensity of the SBA-15@CsPbBr 3 QDs experienced a relatively slower decrease after second, third and fourth time thermal cycle. The mesoporous of SBA-15 are open channel. Therefore, the air and water also can influence the PL intensity of SBA-15@CsPbBr 3 QDs. However, as a template, SBA-15 can inhibit the agglomeration of quantum dots during heating, which can be proved from the fact that the position of PL peak hardly changes with the increasing temperature.
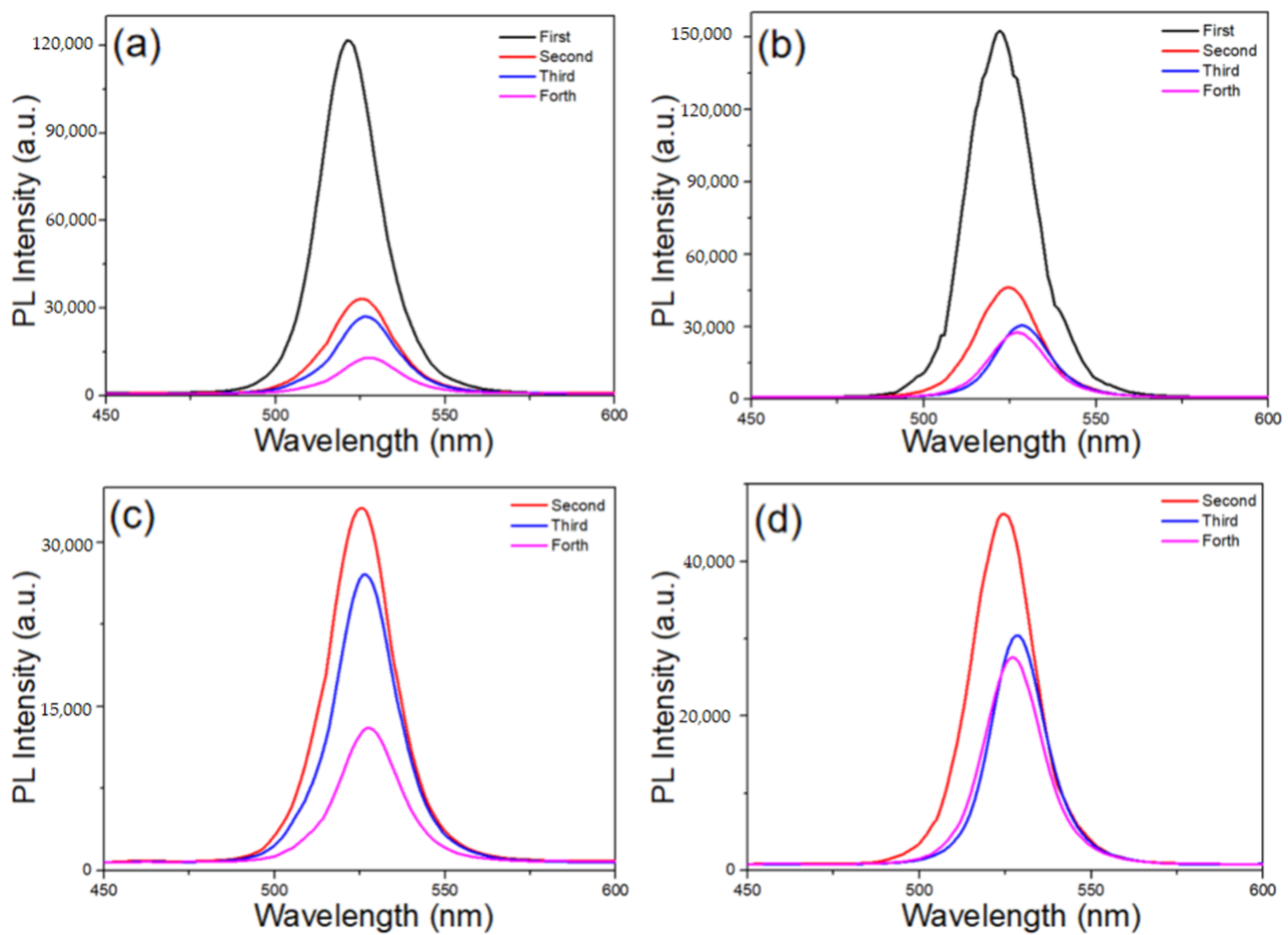

Figure 7. The PL spectra of (a) pure $\mathrm{CsPbBr}_{3}$ QDs and (b) SBA-15 $\mathrm{CsPbBr}_{3}$ QDs after heating and cooling cycle. The PL spectra of (c) pure $\mathrm{CsPbBr}_{3}$ QDs and (d) SBA-15@CsPbBr $\mathrm{QDs}^{\prime}$ heating and cooling cycle for the last three times.

As shown in Figure 8, it was found that all the characteristic peaks of pure $\mathrm{CsPbBr}_{3}$ QDs and SBA-15@CsPbBr 3 QDs could be found after heating and cooling cycle, which indicated that the structure of pure $\mathrm{CsPbBr}_{3}$ QDs and $\mathrm{SBA}-15 @ \mathrm{CsPbBr} 3$ QDs was preserved without destruction. The PL intensity of pure $\mathrm{CsPbBr}_{3}$ QDs decreased significantly mainly due to the falling of ligands (OA or OLA) from the surface of QDs and the additional structural defects caused by the heating. In contrast, the PL intensity of the SBA-15@CsPbBr QDs experienced a relatively slower decrease.

The liquid-type fluorescent LED based on SBA-15@CsPbBr 3 QDs has been fabricated as shown in Figure 9. For the typical fabrication process of LED devices as follows: two large pieces of glass (the size is $1.7 \mathrm{~cm} \times 1.7 \mathrm{~cm}$ with the thickness of $0.1 \mathrm{~cm}$ ) and four thin stripes (two of them: $1.7 \mathrm{~cm} \times 0.3 \mathrm{~cm}$ and the other: $1 \mathrm{~cm} \times 0.3 \mathrm{~cm}$ ) were cut and then cleaned by deionized water and ethanol. These four thin stripes were sandwiched between two large pieces of glass, and a liquid-type glass tank with the size of $1 \mathrm{~cm} \times 1 \mathrm{~cm}$ was left. In addition, the two gaps with the width of $0.1 \mathrm{~cm}$ were left in order to make the air get out of the glass box when liquid-type QDs were loaded. Then the glass box was filled with QD solution and sealed all the gaps with epoxy-based glue. Finally, monochromatic QD-LEDs were fabricated by integrating the sealed glass box with UV LED chip (emission peak at $365 \mathrm{~nm})$. 


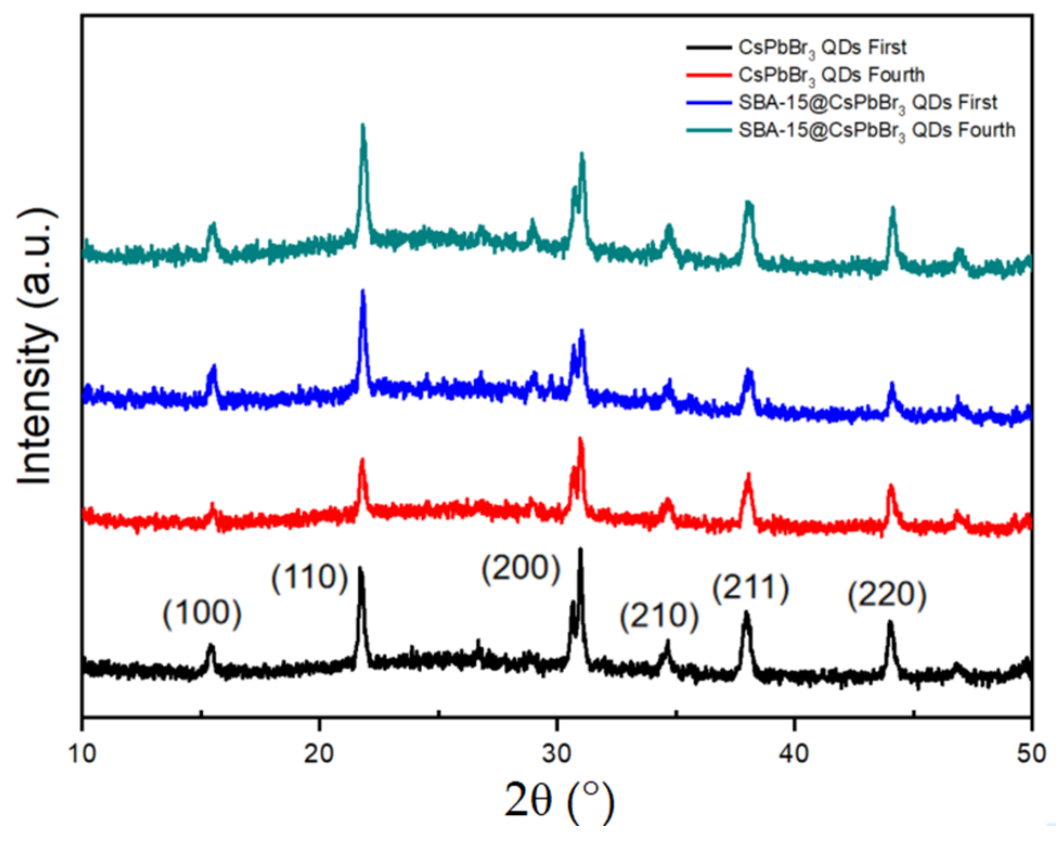

Figure 8. XRD pattern of pure $\mathrm{CsPbBr} 3$ QDs and $\mathrm{SBA}-15 @ \mathrm{CsPbBr}_{3}$ QDs after heating and cooling.

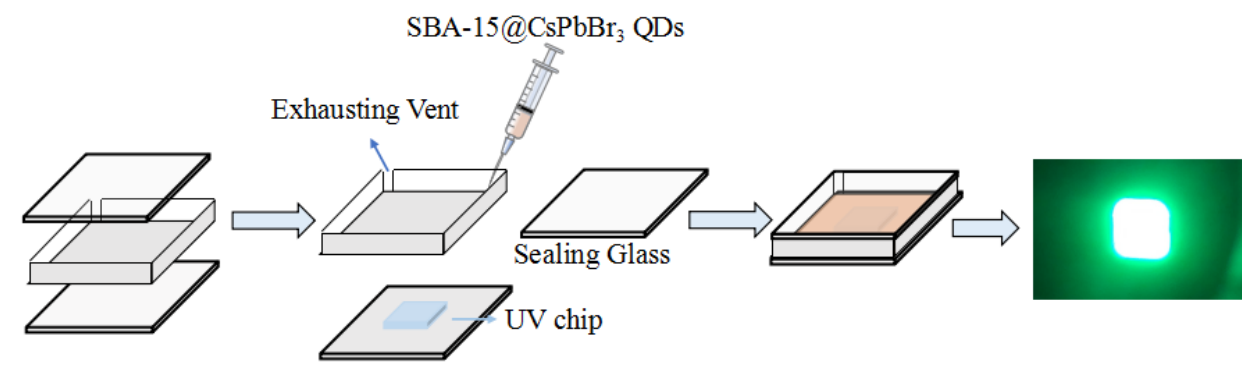

Figure 9. The process flow of liquid-type QD-LEDs and the picture of LED sample with green emission color operated at $3.2 \mathrm{~V}$ under a dark condition.

The luminance of the LED is shown in Figure 10 which was worked on $2.6 \mathrm{~V}, 2.8 \mathrm{~V}$, $3.0 \mathrm{~V}$ and $3.2 \mathrm{~V}$.

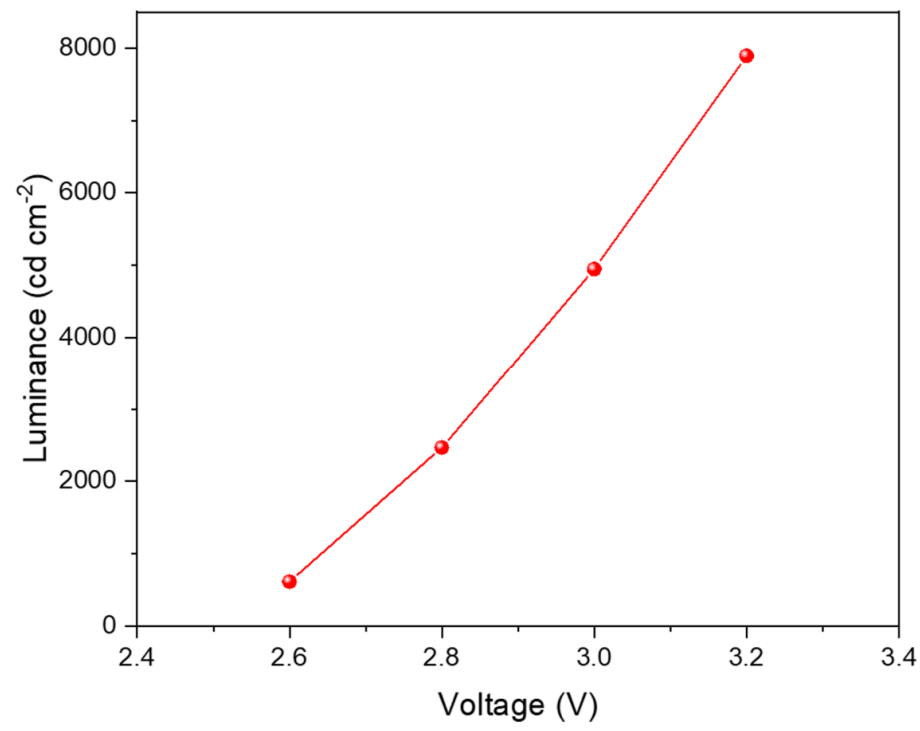

Figure 10. The luminance of SBA-15@CsPbBr 3 QD-LED at different voltage. 


\section{Conclusions}

In summary, by using SBA-15 as the template, the growth of $\mathrm{CsPBr}_{3}$ QDs is controlled in this paper, and the stability of the PQDs is improved by uniform crystallization. Compared with pure $\mathrm{CsPbBr}_{3}$ QDs, the thermal stability of SBA-15@CsPbBr 3 QDs was better. In the heating experiment, the PL intensity of pure $\mathrm{CsPbBr}_{3}$ QDs decreased rapidly and greatly. However, that of SBA-15@CsPbBr 3 QDs decreased more slightly, especially at high temperature. The PL spectra of pure $\mathrm{CsPbBr}_{3}$ QDs has red-shift $(\sim 6 \mathrm{~nm})$ with the increasing temperature, but did not occur at that of SBA-15@CsPbBr 3 QDs. In addition, the PL intensity of SBA-15@CsPbBr 3 QDs decreased less than that of $\mathrm{CsPbBr}_{3}$ QDs significantly after four times of heating and cooling. The results showed that this method can solve the problem of improving the thermal stability of perovskite, which shows a broad prospect in the stability of perovskite. Although the results given in this paper are not perfect, it can provide a new research idea of PQDs based on SBA-15, which will make a significant contribution to improving the stability and practical application of these kinds of materials in the future.

Author Contributions: Data curation, H.C.; writing-original draft preparation, H.C.; investigation, Y.W.; literature search, Y.W.; principal analysis, J.W. interpretation data, J.W.; administration, W.L.; formulation of overarching research goals, W.L. All authors have read and agreed to the published version of the manuscript.

Funding: This research was funded by the National Natural Science Foundation of China, Grant Nos 61604003 and 62005268.

Institutional Review Board Statement: Not applicable.

Informed Consent Statement: Not applicable.

Data Availability Statement: Data sharing is not applicable to this article.

Conflicts of Interest: The authors declare that they have no known competing financial interests or personal relationships that could have appeared to influence the work reported in this paper.

\section{References}

1. Sun, S.; Yuan, D.; Xu, Y.; Wang, A.; Deng, Z. Ligand-mediated synthesis of shape-controlled cesium lead halide perovskite nanocrystals via reprecipitation process at room temperature. ACS Nano 2016, 10, 3648-3657. [CrossRef]

2. Lin, C.C.; Meijerink, A.; Liu, R.-S. Critical red components for next-generation white LEDs. J. Phys. Chem. Lett. 2016, 7, 495-503. [CrossRef] [PubMed]

3. Li, J.; Xu, L.; Wang, T.; Song, J.; Chen, J.; Xue, J.; Dong, Y.; Cai, B.; Shan, Q.; Han, B.; et al. 50-Fold EQE improvement up to $6.27 \%$ of solution-processed all-inorganic perovskite CsPbBr3 QLEDs via surface ligand density control. Adv. Mater. 2017, 29, 1603885-1603894. [CrossRef] [PubMed]

4. Yuan, F.; Yuan, T.; Sui, L.; Wang, Z.; Xiaohong, L.; Li, Y.; Li, X.; Fanglong, Y.; Tan, Z.; Chen, A.; et al. Engineering triangular carbon quantum dots with unprecedented narrow bandwidth emission for multicolored LEDs. Nat. Commun. 2018, 9, 1-11. [CrossRef] [PubMed]

5. Wang, L.; Liu, H.; Zhao, J.; Zhang, X.; Zhang, C.; Zhang, G.; Liu, Q.; Duan, H. Enhancement of charge transport in porous car-bon nanofiber networks via ZIF-8-enabled welding for flexible supercapacitors. Chem. Eng. J. 2020, 382, 122979-123012. [CrossRef]

6. Luyen, D.T.L.; Thanh, T.D.; Chuong, N.D.; Tuan, L.H.; Hoon, K.N.; Hee, L.J. Hierarchical three-dimensional framework interface assembled from oxygen-doped cobalt phosphide layer-shelled metal nanowires for ef-ficient electrocatalytic water splitting. Appl. Catal. 2020, 261, 118268-118281. [CrossRef]

7. Septiani, N.L.W.; Kaneti, Y.V.; Fathoni, K.B.; Wang, J.; Ide, Y.; Yuliarto, B.; Nugraha; Dipojono, H.K.; Nanjundan, A.K.; Golberg, D.; et al. Self-assembly of nickel phosphate-based nanotubes into two-dimensional crumpled sheet-like architectures for high-performance asymmetric supercapacitors. Nano Energy 2020, 67, 104270. [CrossRef]

8. Song, J.; Li, J.; Li, X.; Xu, L.; Dong, Y.; Zeng, H. Quantum dot light-emitting diodes based on inorganic perovskite cesium lead halides (CsPbX3). Adv. Mater. 2015, 27, 7162-7167. [CrossRef]

9. Gul, I.; Sayed, M.; Shah, N.S.; Khan, J.A.; Polychronopoulou, K.; Iqbal, J.; Rehman, F. Solar light responsive bismuth doped titania with $\mathrm{Ti}^{3+}$ for efficient photocatalytic degradation of flumequine: Synergistic role of peroxymonosulfate. Chem. Eng. J. 2020, 384, 123255-123273. [CrossRef]

10. Chu, S.; Chen, W.; Fang, Z.; Xiao, X.; Liu, Y.; Chen, J.; Huang, J.; Xiao, Z. Large-area and efficient perovskite light-emitting diodes via low-temperature blade-coating. Nat. Commun. 2021, 12, 1-9. [CrossRef] 
11. Im, J.-H.; Lee, C.-R.; Lee, J.-W.; Park, S.-W.; Park, N.-G. 6.5\% efficient perovskite quantum-dot-sensitized solar cell. Nanoscale 2011, 3, 4088-4093. [CrossRef] [PubMed]

12. Zhu, Z.; Ma, J.; Wang, Z.; Mu, C.; Fan, Z.; Du, L.; Bai, Y.; Fan, L.; Yan, H.; Phillips, D.L.; et al. Efficiency enhancement of perovskite solar cells through fast electron extraction: The role of graphene quantum dots. J. Am. Chem. Soc. 2014, 136, 3760-3763. [CrossRef] [PubMed]

13. Tang, D.; Liu, J.; Wu, X.; Liu, R.; Han, X.; Han, Y.; Huang, H.; Liu, Y.; Kang, Z. Carbon quantum Dot/NiFe layered doublehydroxide composite as a highly efficient electrocatalyst for water oxidation. ACS Appl. Mater. Interfaces 2014, 6, 7918-7925. [CrossRef] [PubMed]

14. Niu, H.; Yang, X.; Wang, Q.; Jing, X.; Cheng, K.; Zhu, K.; Ye, K.; Wang, G.; Cao, D.; Yan, J. Electrostatic self-assembly of MXene and edge-rich CoAl layered double hydroxide on molecular-scale with superhigh volumetric performances. J. Energy Chem. 2019, 46, 105-113. [CrossRef]

15. Xu, Y.; Wang, R.; Zheng, Y.; Zhang, L.; Jiao, T.; Peng, Q.; Liu, Z. Facile preparation of self-assembled Ni/Co phosphates composite spheres with highly efficient HER electrocatalytic performances. Appl. Surf. Sci. 2020, 509, 145383-145430. [CrossRef]

16. Jellicoe, T.; Richter, J.M.; Glass, H.F.J.; Tabachnyk, M.; Brady, R.; E Dutton, S.; Rao, A.; Friend, R.H.; Credgington, D.; Greenham, N.C.; et al. Synthesis and optical properties of lead-free cesium tin halide perovskite nanocrystals. J. Am. Chem. Soc. 2016, 138, 2941-2944. [CrossRef]

17. Chen, Y.; Zhao, Y. Incorporating quantum dots for high efficiency and stable perovskite photovoltaics. J. Mater. Chem. A 2020, 8, 25017-25027. [CrossRef]

18. Stoumpos, C.; Malliakas, C.D.; Peters, J.A.; Liu, Z.; Sebastian, M.; Im, J.; Chasapis, T.C.; Wibowo, A.; Chung, D.Y.; Freeman, A.J.; et al. Crystal growth of the perovskite semiconductor $\mathrm{CsPbBr3}$ : A new material for high-energy radiation detection. Cryst. Growth Des. 2013, 13, 2722-2727. [CrossRef]

19. Protesescu, L.; Yakunin, S.; Bodnarchuk, M.; Krieg, F.; Caputo, R.; Hendon, C.; Yang, R.X.; Walsh, A.; Kovalenko, M.V. Nanocrystals of cesium lead halide perovskites ( $\mathrm{CsP} \mathrm{PX}, \mathrm{X}=\mathrm{Cl}, \mathrm{Br}$, and I): Novel optoelectronic materials showing bright emission with wide color gamut. Nano Lett. 2015, 15, 3692-3696. [CrossRef]

20. Xiang, X.; Lin, H.; Xu, J.; Cheng, Y.; Wang, C.; Zhang, L.; Wang, Y. CsPb(Br,I)3 embedded glass: Fabrication, tunable luminescence, improved stability and wide-color gamut LCD application. Chem. Eng. J. 2019, 378, 122255. [CrossRef]

21. Aboulaich, A.; Michalska, M.; Schneider, R.; Potdevin, A.; Deschamps, J.; Deloncle, R.; Chadeyron, G.; Mahiou, R. Ce-doped YAG nanophosphor and red emitting CuInS2/ZnS core/shell quantum dots for warm white light-emitting diode with high color rendering index. ACS Appl. Mater. Interfaces 2014, 6, 252-258. [CrossRef]

22. Yang, D.D.; Li, X.M.; Wu, Y.; Wei, C.T.; Qin, Z.Y.; Zhang, C.F.; Sun, Z.G.; Li, Y.L.; Wang, Y.; Zeng, H.B. Surface halogen compensation for robust performance enhancements of CsPbX3 perovskite quantum dots. Adv. Opt. Mater. 2019, 7, 1900276. [CrossRef]

23. Long, Z.; Ren, H.; Sun, J.H.; Ouyang, J.; Na, N. High-throughput and tunable synthesis of colloidal CsPbX3 perovskite nanocrystals in a heterogeneous system by microwave irradiation. Chem. Comm. 2017, 53, 9914-9917. [CrossRef] [PubMed]

24. Dong, Y.; Tang, X.; Zhang, Z.; Song, J.; Niu, T.; Shan, D.; Zeng, H. Perovskite nanocrystal fluorescence-linked immunosorbent assay methodology for sensitive point-of-care biological test. Matter 2020, 3, 273-286. [CrossRef]

25. Shamsi, J.; Urban, A.S.; Imran, M.; De Trizio, L.; Manna, L. Metal halide perovskite nanocrystals: Synthesis, post-synthesis modifications, and their optical properties. Chem. Rev. 2019, 119, 3296-3348. [CrossRef]

26. Swarnkar, A.; Chulliyil, R.; Ravi, V.K.; Irfanullah, M.; Chowdhury, A.; Nag, A. Colloidal CsPbBr3 perovskite nanocrystals: Lu-minescence beyond traditional quantum dots. Angew. Chem. Int. Ed. 2015, 54, 15424-15428. [CrossRef]

27. Wu, K.; Liang, G.; Shane, Q.; Ren, Y.; Kong, D.; Lian, T. Ultrafast interfacial electron and hole transfer from CsPbBr3 perovskite quantum dots. J. Am. Chem. Soc. 2015, 137, 12792-12795. [CrossRef] [PubMed]

28. Wang, H.-C.; Lin, S.-Y.; Tang, A.-C.; Singh, B.P.; Tong, H.-C.; Chen, C.-Y.; Lee, Y.-C.; Tsai, T.-L.; Liu, R.-S. Mesoporous Silica Particles Integrated with All-Inorganic CsPbBr3 Perovskite Quantum-Dot Nanocomposites (MP-PQDs) with high stability and wide color gamut used for backlight display. Angew. Chem. Int. Ed. 2016, 55, 7924-7929. [CrossRef] [PubMed]

29. Pan, A.; He, B.; Fan, X.; Liu, Z.; Urban, J.J.; Alivisatos, A.P.; He, L.; Liu, Y. Insight into the ligand-mediated synthesis of colloidal CsPbBr3 perovskite nanocrystals: The role of organic acid, base, and cesium precursors. Acs Nano 2016, 10, 7943-7954. [CrossRef]

30. Zhang, X.; Xu, B.; Zhang, J.; Gao, Y.; Zheng, Y.; Wang, K.; Sun, X. All-inorganic perovskite nanocrystals for high-efficiency light emitting diodes: Dual-phase CsPbBr3 -CsPb2 Br5 composites. Adv. Funct. Mater. 2016, 26, 4595-4600. [CrossRef]

31. Zhang, J.; Bai, D.; Jin, Z.; Bian, H.; Wang, K.; Sun, J.; Wang, Q.; Liu, S. 3D-2D-OD interface profiling for record efficiency all-inorganic CsPbBrI2 perovskite solar cells with superior stability. Adv. Energy Mater. 2018, 8, 1703246-1703255. [CrossRef]

32. Yang, H.; Yin, W.; Dong, W.; Gao, L.; Tan, C.-H.; Li, W.; Zhang, X.; Zhang, J. Enhancing the light-emitting performance and stability in $\mathrm{CsPbBr} 3$ perovskite quantum dots via simultaneous doping and surface passivation. J. Mater. Chem. C 2020, 8 , 14439-14445. [CrossRef]

33. Guo, Q.; Yuan, F.L.; Zhang, B.; Zhou, S.J.; Zhang, J.; Bai, Y.M.; Fan, L.Z.; Hayat, T.; Alsaedi, A.; Tan, Z.A. Passivation of the grain boundaries of $\mathrm{CH} 3 \mathrm{NH} 3 \mathrm{PbI} 3$ using carbon quantum dots for highly efficient perovskite solar cells with excellent environmental stability. Nanoscale 2019, 11, 115-124. [CrossRef] 
34. Krieg, F.; Ochsenbein, S.T.; Yakunin, S.; Brinck, S.t.; Aellen, P.; Suess, A.; Clerc, B.; Guggisberg, D.; Nazarenko, O.; Shynkarenko, Y.; et al. Colloidal CsPbX3 (X = CI, Br, I) nanocrystals 2.0: Zwitterionic capping ligands for improved durability and stability. ACS Energy Lett. 2018, 3, 641-646. [CrossRef] [PubMed]

35. Kojima, A.; Ikegami, M.; Teshima, K.; Miyasaka, T. Highly Luminescent lead bromide perovskite nanoparticles synthesized with porous alumina media. Chem. Lett. 2012, 41, 397-399. [CrossRef]

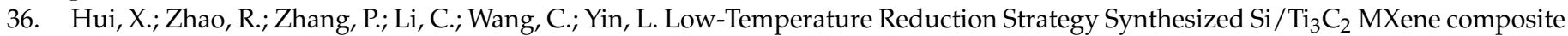
anodes for high-performance li-ion batteries. Adv. Energy Mater. 2019, 9, 1901065. [CrossRef]

37. Zhang, X.; Bai, X.; Wu, H.; Zhang, X.; Sun, C.; Zhang, Y.; Zhang, W.; Zheng, W.; Yu, W.W.; Rogach, A.L. Water-assisted size and shape control of $\mathrm{CsPbBr} 3$ perovskite nanocrystals. Angew. Chem. Int. Ed. 2018, 57, 3337-3342. [CrossRef]

38. Huang, S.; Li, Z.; Kong, L.; Zhu, N.; Shan, A.; Li, L. Enhancing the stability of CH3NH3PbBr3 quantum dots by embedding in silica spheres derived from tetramethyl orthosilicate in "Waterless" toluene. J. Am. Chem. Soc. 2016, 138, 5749-5752. [CrossRef]

39. Raja, S.N.; Bekenstein, Y.; Koc, M.A.; Fischer, S.; Zhang, D.; Lin, L.; Ritchie, R.O.; Yang, P.; Alivisatos, A.P. Encapsulation of perovskite nanocrystals into macroscale polymer matrices: Enhanced stability and polarization. ACS Appl. Mater. Interfaces 2016, 8, 35523-35533. [CrossRef]

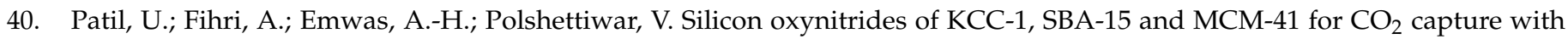
excellent stability and regenerability. Chem. Sci. 2012, 3, 2224-2229. [CrossRef]

41. Boutros, M.; Maoui, Z.; Sfihi, H.; Viossat, V.; Gédéon, A.; Launay, F. Effect of the anchorage of Rh(III) ions by imidazoline type ligands on the location of Rh0 particles within the calcined form of the SBA-15 support. Microporous Mesoporous Mater. 2008, 108, 247-257. [CrossRef]

42. Mandache, I.; Parvulescu, V.I.; Popescu, A.; Parvulescu, L.; Banciu, M.D.; Amoros, P.; Beltran, D.; On, D.T.; Kaliaguine, S. Epox-idation of dibenzocycloalkenes on Ti-Ge-MCM-41 and Ti-SBA-15 catalysts. Microporous Mesoporous Mat. 2005, 81, 115-124. [CrossRef]

43. Sousa, W.R.D.N.; Oliveira, A.R.; Filho, J.F.C.; Dantas, T.C.M.; Santos, A.G.D.; Caldeira, V.; Luz, G.E. Ciprofloxacin adsorption on ZnO supported on SBA-15. Water Air Soil Pollut. 2018, 229, 125. [CrossRef]

44. Colmenares, M.G.; Simon, U.; Schmidt, F.; Dey, S.; Schmidt, J.; Thomas, A.; Gurlo, A. Tailoring of ordered mesoporous silica COK-12: Room temperature synthesis of mesocellular foam and multilamellar vesicles. Microporous Mesoporous Mater. 2018, 267, 142-149. [CrossRef] 